This item was submitted to Loughborough's Research Repository by the author.

Items in Figshare are protected by copyright, with all rights reserved, unless otherwise indicated.

\title{
Exploring disaster ontologies from Chinese and Western perspectives: commonalities and nuances
}

PLEASE CITE THE PUBLISHED VERSION

https://doi.org/10.1108/DPM-03-2021-0108

PUBLISHER

Emerald Publishing Limited

VERSION

AM (Accepted Manuscript)

\section{PUBLISHER STATEMENT}

This paper was accepted for publication in the journal Disaster Prevention and Management and the definitive published version is available at https://doi.org/10.1108/DPM-03-2021-0108.

LICENCE

CC BY-NC 4.0

\section{REPOSITORY RECORD}

Goodall, Susie, Yajun Li, Ksenia Chmutina, Tom Dijkstra, Xingmin Meng, and Colm Jordan. 2021. "Exploring Disaster Ontologies from Chinese and Western Perspectives: Commonalities and Nuances”. Loughborough University. https://hdl.handle.net/2134/17013140.v1. 


\section{Exploring disaster ontologies from Chinese and Western perspectives: commonalities and nuances}

Goodall, Susie; Li, Yajun; Chmutina, Ksenia; Dijkstra, Tom; Meng, Xingmin; Jordan, Colm

\section{Structured abstract}

\section{Purpose}

This paper explores ontological assumptions of disasters and introduces some concepts from Chinese disaster scholarship. We suggest an approach to explore and engage with different ontologies of disaster without direct comparison, that can further interdisciplinary and crosscultural collaboration.

\section{Approach}

By reviewing the academic literature and focusing on two recent key translational texts by Chinese scholars, we show what can be revealed about ontology and the potential influence on thinking about human-environment interactions and Disaster Risk Reduction policy.

\section{Findings}

In Chinese disaster studies, the goal of a 'harmonious human-environment relationship' is a foundational concept. There is a clear hierarchical and ontological distinction between humans and the natural ecological system viewed as an integrated whole, with underlying rules that can be discovered by scientific research to enable management of a harmonious relationship.

\section{Originality}

Identification of ontological differences in interdisciplinary and cross-cultural research collaborations and working across these boundaries is challenging and rarely questioned. Yet, as demonstrated here, considering ontological assumptions of the causes of disaster, within and across cultures and disciplines, is essential for collaboration and further research.

\section{Practical implications}


We suggest a practical way to begin with the following questions: What is the societal goal/aim? What is nature? What is society? How do these interact to create disasters? And what are the implications for DRR research and practice? We also demonstrate the importance of probing and understanding the underlying ontologies that are the foundation for theory, which is in turn is the foundation for policy and action.

\section{Introduction}

Inter-national, inter-cultural and inter-disciplinary hazard and disaster science collaborations have become the norm in an increasingly global approach to better understand and address human-landscape interactions. Ideally, these collaborations would bring a richness of perspectives and expertise alongside new challenges of cross-cultural awareness and communication. Yet, a predominance of a Western scientific paradigm in disaster research and practice agendas (Gaillard, 2019) can limit effective communication and dialogue. There is a need to look more closely at how different countries and cultures respond to disasters and make efforts to reduce disaster risk. This can reveal important nuances in underlying assumptions and beliefs. Broadening the range of perspectives and voices in academic discourse (e.g. decolonising methodologies (Smith, 2012); participatory research (Chambers, 1994); community-based disaster risk reduction (Bhatt and Gaillard, 2020); the 'Power, Prestige and Forgotten Values' manifesto (n.a., 2019)) is the goal of many - but more work is required.

Scientific thought and practice are embedded within socio-cultural contexts, with varying goals, concepts and language (Feyerabend, 1978; Kuhn, 1970). Vocabulary and meaning will not necessarily map directly between languages and contexts. For instance, Chmutina et al. (2020) show how the translation of common disaster terminology between global and 'peripheral' languages can lead to English-language scientific hegemony. Terms translated into English tend to be 'domesticated', adopting English structures and meaning, and thus there is a risk that these lose their original conceptual sense, if different from typical anglophone usage. Terms translated from English tend to be 'foreignised'; i.e. they keep their original style and conceptual meaning, which are potentially disruptive in the target language and culture. In other words, the use of Anglophone terminology - and underlying meaning enforces power by creating language norms but these meanings are limited as they emerge from ideological perspectives and can demonstrate political agendas. 
This paper is a result of conversations that emerged in research teams comprising Chinese academics based in China who have worked in the UK (and who speak English), and UK-based academics who have worked in China (some of whom speak Mandarin) over the course of many years. In order to narrow the scope, we focus on geohazards as our area of expertise. Rather than provide a definitive work on Chinese philosophy and concepts of disaster (which would be beyond the expertise of the authors), we explore concepts, language and meaning from the literature and the direct experience of the co-authors. We aim to explore how considering ontology (i.e., the underlying beliefs about reality) can be a useful tool for dialogue in cross-cultural disaster research. We outline what we mean by ontology, followed by framing the Western (Anglophone) and Chinese perspectives on disaster risk reduction (DRR). It is important to highlight that we consider these perspectives, not as binary or opposing monolithic blocks, but as nuanced trends in thinking, with commonalities and differences. There is merit in exploring the distinctive aspects of these trends, with the aim of increasing mutual understanding. We then focus in more detail on two key sources of 'translational' literature written in English by Chinese scholars (Fan, 2016; Shi, 2019) with the aim of exploring the Chinese ontology of disaster. Both sources include important concepts that are relevant to how disasters are conceptualised, and risks are managed. And both are characterised by limited 'domestication' of Chinese concepts and terms when translated into English. From these recent sources we analyse concepts and ontology of 'disaster' and human-environment interactions from a Chinese perspective, which in turn allows reflection on and critique of what might be considered 'mainstream' DRR perspectives and global agendas.

In recent years, China has become a major global contributor of scientific research, both in English and Chinese language journals. A search in the database Scopus for the term 'disaster' (accessed $2^{\text {nd }}$ Feb, 2021) yielded 172,071 results, of which China was the second largest contributing country (after the USA), with $16.5 \%$ of research papers overall, and $49 \%$ of the listed non-English publications. The Chinese Academy of Sciences and Ministry of Education were the two largest single affiliations for authors. A search in the China National Knowledge Infrastructure website (accessed 19 ${ }^{\text {th }}$ Feb, 2021) for the same term ('disaster', in English) yielded 173,156 academic journal papers published in Chinese, while the Chinese equivalent (灾害) yielded 410,269 journal papers. 
For most of the international research community, engagement with research by Chinese scholars necessarily takes place in English. This can mask differences in meaning and conceptualisation. There is a danger that terms can be used without an understanding of their underlying meanings. For example, the term used in Chinese for a 'disaster' caused by natural hazards - 自然灾害 - is directly translated into English as 'natural disaster'. Calling a disaster 'natural' has been challenged in the English-speaking disaster studies literature (e.g. O'Keefe et al. (1976); Chmutina and von Meding (2019) and others) as it implies that disasters are caused only by natural processes rather than underlying social causes embedded within structural inequalities in a society. The translation of 自然灾害 to 'natural disaster' is not necessarily making a point in the debate about use and meaning of the term 'natural disaster'. However, it does raise the question of what concepts the term 自然灾害 is expressing. Thus, in discussing the language, meaning and cause of disaster, we already approach the realms of ontology in thinking about what is 'natural' or nature, what is society, and how these interact in ways that generate consequences for humans.

A shift in the debate towards ontology as a foundation for considering different perspectives is explored in this paper, to allow posing important questions that underpin disaster studies what are the ontological assumptions behind different views on the causes of disasters? How do these assumptions influence DRR research and practice? What does this mean for multinational and multi-cultural research collaboration? The implications of failing to consider the different ontological assumptions within and across cultures are far-reaching, as we risk missing these assumptions altogether and failing to find points of integration as well as dismissing other knowledges and ways of seeing the world and the insights they bring. In DRR, failing to understand the ontological roots of theory, policy and action stifles healthy debate and dialogue, potentially leading to less effective outcomes.

\section{What is ontology? The philosophical underpinning of this paper}

In Western scientific thought, ontology is the philosophy of reality that addresses the question, "what kinds of things are there in the world?". There are a wide variety of ontological positions, from idealism (ultimate reality is human consciousness), to materialism (only matter is real), or agnosticism (the true nature of the world cannot be known) (Benton and Craib, 2001). Within a discipline or field of study, ontologies may be implicit and assumed, 
or much debated and researched (notably, in geography and computer science (Cablitz, 2001; Kai et al., 2017; Tambassi, 2017)).

A discussion of ontology also comes to the fore in cases where research is interdisciplinary (Danermark, 2019) and/or is cross-cultural. Here, a shared implicit disciplinary ontology can no longer be assumed, and a deeper dive into ontological boundaries, categories, and concepts is needed. Without this, research may be critiqued based on different reference viewpoints, and dialogue becomes difficult at best - and irrelevant at worst. An exception to this is perhaps the highly numerical disciplines, in which mathematics becomes a shared language (Parker Waller and Flood, 2016). Nonetheless, even here we cannot escape the need for dialogue and understanding around how numerical models are developed and used, for society's benefit.

In using the term 'Chinese ontology', we are immediately faced with a dilemma: we are using Western terminology to explore Chinese philosophical thought, rather than letting it speak on its own terms. Indeed, there is debate about whether ontology exists in Chinese philosophy, at least in the same sense as European philosophy, as it can be considered to have more of a focus on political and ethical issues than metaphysics (Perkins, 2019), or perhaps engage in different kinds of inquiry altogether (von Norden, 2017). Here we limit our discussion of ontology to what is relevant for human-environment interactions, humans, nature, and disasters. The importance of probing and understanding the underlying ontologies is that they are the foundation for theory, and theory in turn is the foundation for policy and action.

\section{Western disaster risk reduction perspectives}

DRR is defined as efforts to "analyse and manage the causal factors of disasters, including through reduced exposure to hazards, lessened vulnerability of people and property, wise management of land and the environment, and improved preparedness for adverse events" (UNDRR, 2009, p.10). DRR research and practice have informed international frameworks that seek to promote and further DRR efforts. The Hyogo Framework for Action (2005-2015) aspired to achieve "the substantial reduction of disaster losses, in lives and in the social, economic and environmental assets of communities and countries", while the subsequent Sendai Framework for Disaster Risk Reduction (2015-2030) (SFDRR) calls ratifying states to: 
"Prevent new and reduce existing disaster risk through the implementation of integrated and inclusive economic, structural, legal, social, health, cultural, educational, environmental, technological, political and institutional measures that prevent and reduce hazard exposure and vulnerability to disaster, increase preparedness for response and recovery, and thus strengthen resilience".

SFDRR, as all other DRR initiatives, aims to build the link between science and policy, largely through quantification as the predominant and widely employed legitimate way to measure progress. Such international frameworks reflect a Western ${ }^{1}$ modernist $^{2}$ approach to DRR. Conceived as a result of international development narratives deeply rooted in neoliberal ${ }^{3}$ context, the evolution of DRR frameworks under neoliberalism suggests that they are not "bad" in and of themselves. They offer good faith understandings of the limits of disaster mitigation and recovery and offer possible solutions. The issue is that the possible solutions are curtailed by belief in the ideology of neoliberal development (Saull, 2017). Development was seen to become the stabilising factor in the post-war world, with globalisation and therefore urbanisation as drivers of stability. In the 'developed', yet damaged world, this prosperity was to be revived. In the 'developing' world, this dynamic was brought about through policy and restructuring (Cheek and Chmutina, 2021). Understanding the roots of these approaches and their philosophical grounding is critical, to avoid making assumptions that these views are normative and allow for appropriate critique.

How have Western academics approached the question of nature, society, and their interactions? Castree \& Braun (2001) identify three approaches within Geography, a discipline uniquely situated to study the interdisciplinary area between physical and social science. One mainstream approach, advocated by Stoddart (1987), focuses on the human-environment interactions that are the major challenges facing society such as climate change, pollution,

\footnotetext{
${ }^{1}$ Here, "Western" is wrapped up in the Eurocentric ideas of civilisation and progress, stemming from the time when Europeans believed themselves to be the only 'west'. Today it is used, ironically, to refer to "better", "more civilised", "more developed", when it might more easily point to achievements such as colonialism, capitalism, monotheism, racism, and patriarchy.

${ }^{2}$ Modernism has its roots in $17^{\text {th }}$ century Enlightenment thinking that ushered in an age of belief in human reason and the power of scientific knowledge and technology to improve and reshape the physical environment.

${ }^{3}$ A neoliberal paradigm, whilst contradictory and polymorphic (Peck, 2010), is used here in general terms as a programme and ideology of privatisation, deregulation, the global movement of capital that entrenched itself throughout the global north in the 1970s and beyond.
} 
deforestation etc. Critiques of this approach include its limitation of nature to 'environmental problems', the technocratic knowledge it produces and its focus on addressing impacts such as pollution without addressing underlying causes in the socioeconomic system (Castree \& Braun, 2001). 'Ecocentric' approaches on the other hand argue for the need to respect nature and put its interests first, calling for fundamental changes to systems of production. A third approach argues that nature is "inescapably social...and is defined, delimited and even physically reconstituted by different societies, often in order to serve specific, and usually dominant, social interests" (p.3). This social nature approach implies that the social and the natural are so entwined that they cannot be separated. In DRR, we see a shift towards ecocentric and social approaches, reflected in narratives of working with nature e.g. making space for water (Van Buuren et al., 2012) and nature-based solutions for flood risk management.

\section{Chinese context and DRR perspectives}

Spanning over 9.6 million $\mathrm{km}^{2}$, China has a vast range of climatic zones and terrain (Fan, 2016), including the tallest tectonically active mountain range on earth, the high plateau of Tibet, extensive deserts, sub-tropical karst landscapes, and large dynamic river plains. Wang et al. (2020) comprehensively classifies the terrain into 25 geomorphological zones. The simple conceptualisation of a staircase-like topography, with decreasing elevation from west to east, is used to partly explain the distribution of geological hazards at the steep transitions between steps (Shi et al., 2016). The country has a long history of disasters and their management. Five thousand years ago the legendary Da Yu prevented catastrophic flooding of the Yellow River (Luo et al., 2015). From then on, China can be considered a hydraulic civilisation, where the agricultural system was dependent on large-scale government-managed water infrastructure for both productive and preventive purposes (Wittfogel, 1957). Examples include the Dujiangyan irrigation infrastructure in Sichuan and the Lingqu Canal in Guangxi, built in the Qin Dynasty (221 to 206 BC). Subsequently, the government - and not the individual, family or community - was the main actor in disaster governance. Chen (2016) finds however that there was "more attention to short-term relief efforts than time-consuming preparatory and preventive actions" in ancient times (p.18).

The Chinese government strategy for dealing with disasters has evolved in more recent history. From the establishment of the People's Republic of China in 1949, social and 
economic development policy has been implemented through five-year government plans. Initially, industrial growth was prioritised (following Soviet models for a centrally planned economy), resulting in rapid economic growth alongside significant environmental impacts. The 'Reform and opening up' era from 1978 brought the establishment of a Ministry of Civil Affairs which had responsibility for disaster management (Chen, 2016). The $6^{\text {th }}$ five-year plan (1981-1985) mentions environmental protection for the first time, though this is mainly related to pollution control. The $9^{\text {th }}$ five-year plan (1996-2000) includes two major strategies for economic development that are relevant here - relying on science and education, and achieving sustainable development, with a call to 'step up research and application of new technologies in such areas as...environmental protection...and the prevention and reduction of natural calamities' (Li, 1996). By the $11^{\text {th }}$ five-year plan (2006-2010), preventing disasters becomes a cross-cutting theme, across poverty reduction, urban planning, information systems and public safety (State Council of China, 2006), in the context of maintaining longterm social stability for development. Coutaz (2018) identifies changes in DRR strategies from the 12th and 13th five-year plans (2011-2020), aligned with disasters viewed as a threat to stability and economic development. Zhang et al. (2018) report on trends in disaster management since 1949, noting a move towards managing disasters to maintain social harmony, more openness to the participation of civil society, and also how particular disasters have triggered policy changes. Driving efforts are the goals of economic and social stability (a moderately prosperous society for all), growth, and sustainable development. Such historical overviews are important, not just for understanding the change in frequency of extreme events, but also for the cultural and institutional history that shapes responses (Luo et al., 2015).

The current situation is made more complex in view of global climate change, rapid economic development and accelerating urbanisation (Jiang, 2013). A report on disaster risks in China highlights the impact of climate change in increasing the frequency and intensity of disasters, through increased intensity of rainfall, droughts and heatwaves. Riverine and flash flooding, as well as geological hazards such as landslides and debris flows are likely to become more frequent as a result (GFDRR, 2020). The same report points out that half of China's population live in areas exposed to natural hazards. An analysis of an inventory of fatal landslides in China from 1950 to 2016 showed that large fatal landslide events (fatalities $>30$ ) increased from 
1950 to 1999 , with a subsequent decline to 2016 attributed to investment in landslide mitigation, while small and medium events (fatalities <10) continued to increase, possibly linked to urbanisation and an increase in extreme rainfall events (Lin and Wang, 2018). Froude and Petley (2018) found that, whilst most landslides in China (as globally) are triggered by rainfall and earthquakes, $9 \%$ are linked to construction (52\% of these in urban construction sites), raising the issue of human activity increasing disaster risk.

Current policy focuses on "comprehensive disaster reduction", integrating it into governance structures, using legal, regulatory, market and technological tools, and holistic planning, as demonstrated in the National Comprehensive Disaster Prevention and Reduction Plan, 20112015 (Jiang, 2013). Other national policies relevant to hazards and vulnerability include the Poverty Reduction Strategy and Central planning policy.

Within the wider national context, China has been officially aiming to become an 'ecological civilisation' (生态文明) since the 18th National Congress in 2012, recognising the environmental damage caused by rapid industrialisation, that can undermine development. Ecological civilisation, "considers nature to be part of life, rather than something that can be exploited without restraint" (Kuhn, 2019, p.1) and has become a major ideological reference framework for top-level environmental governance in China. It embraces the sustainable development agenda - but with Chinese approaches and linked to Chinese philosophical roots. Fan (2016) links this new era to the process of economic development through three stages agricultural civilisation, industrial civilisation, and ecological civilisation - showing continuity with the past.

The Chinese case does not fit within the top-down vs. bottom-up approaches expounded in DRR literature, or into economic 'developed'/'developing' categories but must be considered as a case on its own. Chinese thought has been influenced by Confucianism, Taoism, Buddhism and today's dialectic materialism, among others. Researchers with this cultural and intellectual background are developing novel approaches and theory for considering disasters, from different assumptions. Analysis of these approaches is a fruitful area of research for understanding how culture and ontology influence DRR at a higher level. For example, the government plays a different role in DRR in China (as a country with a socialist market economy and centralised power), compared with other modes of government (Shi, 2012). 
Therefore, the policy options that are developed and preferred will be different from countries with other forms of government. We must research and critique DRR policies with due consideration for and insight into their ontology and cultural context in order to have productive cross-cultural engagement. Within this context, what concepts about humans and the natural environment developed in China and how do they impact DRR today?

\section{Key concepts in Chinese approaches to disaster studies}

Chinese researchers have been developing unique approaches for studying disasters rather than directly lifting concepts such as vulnerability, resilience and adaptation from the existing literature. Fan's (2016) book “How Chinese Human Geographers influence decision makers and society" presents theories developed by Chinese human geographers for the anglophone research community. Whilst influenced by Western, often Marxist academics, they mould and contextualise these ideas with unique Chinese thought.

As Fan and his co-authors explain (2016), implicit in Chinese human geography is the aim to support national strategic demands and resolve major national needs, such as the need to produce food for a large population with limited agricultural land. It is fundamentally practical rather than theoretical. Meeting these needs drives research efforts and has led to substantial influence on decision-making for development. This is in contrast with the critical tradition in western geography, which often has an agenda for social change. As the book is written with the aim of communicating this body of theory for English-speaking academic audiences ${ }^{4}$, it is a good place to begin our study - and therefore served as a 'conversation starter' about Chinese disaster scholarship among the co-authors. We identify key themes and some of their implications.

\section{Goal of a harmonious human-environment relationship}

China has taken a regional approach to 'sustainable development' (可持续发展), focusing on land spatial planning based on the theoretical concepts of 'major function-oriented zoning' (主体功能区划) and 'territorial function theory' (地域功能理论). This is built on the basis that

\footnotetext{
${ }^{4}$ The book is part of the Geographical Society of China Book Series, written by the most prominent scholars in Human Geography in China. The stated aim is to highlight (in seven case studies) how Chinese Human Geographers have contributed to the development of society. While it is not a comprehensive summary of all theory and knowledge in the field, it is crucially how these scholars choose to present their work with a view to sharing these achievements with the wider world.
} 
each region has different geographical characteristics and natural resources and should thus have a specific role or function in China's development - possible in a centrally planned economy. 'Environmental carrying capacity' (环境承载力) ${ }^{5}$ - a concept that has largely fallen out of favour in the West - is a major concept used by Chinese scientists in defining these functions.

The overall goal, nonetheless, remains "to achieve coexistence of human beings and natural ecological system" (Fan, 2016, p.252) - a 'harmonious human-environment relationship' (和 谐的人地关系) - by balancing human demands for living and production space without damaging the 'natural ecological system' (自然生态系统), to the extent that it can no longer support human activity. Critical to this endeavour is the need to understand the spatial characteristics and layout of the territory. Fan (2016) analyses the spatial layout of the Earth's surface into the distinct categories of ecological space, living space, and production space. He argues that human needs for living and production space will disrupt the natural ecological system and hence should be carefully planned to ensure sustainable development. To sustain development, regions with high carrying capacity should have high levels of social and economic activity, while areas with "high ecological value" should be protected, as he recognises the difficulty in achieving both economic development and ecological environmental protection. Shi (2019) also concludes that "the contradiction between the development and the protection be coordinated by designating main functional regions" (p.63).

There is a clear ontological distinction here between humans and the 'natural ecological system'. In Chinese human geography, this relationship has changed through time. In an agricultural civilisation, human activity is determined primarily by geographical conditions, even where government-managed irrigation schemes existed. In an industrial civilisation (for China from 1978), human activity exploits the natural resources available for economic growth leading to pollution and negative impacts on the environment. Fan (2016) attributes this to the lack of scientific basis in economic planning. Driven by top-level leadership, China is now aiming to become an ecological civilisation where human knowledge of the

\footnotetext{
${ }^{5}$ Carrying capacity is primarily an ecological term, referring to the maximum population of a species that can be sustained by the available resources over time.
} 
environment is able to optimally regulate the human-environment relationship (Chen et al., 2020).

In the context of disasters, extensive losses are thus perceived to be a result of failure to consider resources and environmental conditions in planning and construction and, consequently, a "failure to coordinate the human-environment relationship" (Fan, 2016, p.301). Following the 2008 Wenchuan earthquake, human geographers conducted immediate intensive research on carrying capacity to inform rebuilding policy for the first time

- whether to rebuild in the same locations or elsewhere. Their calculations of carrying capacity resulted in ideal numbers of people who should live in each county, that were used for spatial planning for reconstruction.

\section{Human and society}

In Fan's ontology, the world can be divided into 'natural' (自然) and 'human' (人类) elements. This leads to a further question of how the human system is defined and factored in to planning for a harmonious relationship. Fan breaks down human elements into population, industry, and facilities, using predominantly economic terms and metrics. In Shi's "Natural Disaster System of China" (2016), the human elements of the disaster system are primarily considered as exposure units, including population, livestock and crops, buildings, transportation, lifeline systems (including water, electricity, communications etc.), and production systems. Damage to these elements leads to disaster losses. In this ontology, society is where human activity takes place, referring to tangible rather than intangible elements like social networks and culture.

The thinker Liang Shuming reflected on the differences between society in China and the West using the fundamental social structures of individual, family, and community, noting that China is a strongly family-oriented society, compared with the individual focus of the West (Lu and Zhao, 2009). China's best-known sociologist, Fei Xiaotong, suggests that in Chinese family and village life, the important entities are individual, family and state, as opposed to any broader definition of society (Barbalet, 2020). Both Liang Shuming and Fei Xiaotong recognise these strong influences of Confucianism in Chinese culture. Ha (2018) notes that under the influence of Confucianism, China's disaster management system emphasises 
planning, which has been successful in reducing risks. The implications of this ontology of human/society for the way disaster risks are managed is a salient area for further research.

\section{Hierarchy in the human-environment relationship}

"Human is the master of land and geographic environment is the one that could be known, used, changed and protected by man. Harmonious human-environment relationship depends on human rather than environment." (Fan, 2016, p.179)

Within Fan's ontology, there is a clear hierarchy in which humans are the 'masters' of the land and should actively use and change it for their own advantage. The natural ecological system should be protected, because otherwise irreversible damage would threaten human survival, but its value is not intrinsic, rather in how it serves human purposes.

\section{Human society and the natural environment are an integrated whole} Fan (2016) highlights:

"Human society and geographic environment are regarded as an integrated whole. And the understanding about the interaction and feedback effect between human and nature on the surface of the earth or about human-environment relationships is just the core of geographic research and a long-lasting task for theoretical study of geography. [...] Chinese human geography scholars [...] believe that, in order to better deal with the relationships between rational land use and protection, the two systems of human society and geographic environment need to be studied as a whole and the principles, functions and structures for their interaction as well as approaches and countermeasures for overall regulation should be studied so as to provide support for proper and effective environmental development and protection, formulation of suitable land administration plan and development of social and economic strategies" (authors' underline, p.178)

This may have roots in Buddhist metaphysics where everything is interconnected and a cyclic reality. More recently, the writing of Qian Xuesen on engineering cybernetics (1954) has been influential. His work aimed to "organise the design principles used in engineering practice into a discipline and thus to exhibit the similarities between different areas of engineering practice and to emphasise the power of fundamental concepts" with the primary concern being "the 
interrelations among the various components of a system and the synthetic behaviour of the complete mechanism" (p.vii). Regardless of the philosophical roots, this integration of humans and the natural world is becoming increasingly clear, and the goal of studying and understanding the interactions between them are critical for human survival, as the climate crisis shows. The commitment in Chinese human geography to studying integrated systems is important for all research into human-environment interactions.

Shi (2019) identifies and references three schools of thought in disaster theory - hazard, disaster-formative environment, and exposure. Hazard theory classifies hazards and studies their mechanisms and resulting risks (including prediction and early warning) (e.g. Gad-el-Hak, 2008). Disaster-formative environment (孕灾环境) is an unfamiliar term to the anglophone reader. For Shi, the term refers to theories that relate global environmental change to risk, for example how climate change may influence the frequency of hurricanes or how increasing urbanisation affects risk (e.g. Eddy, 1986). Exposure theory (e.g. Carrara and Guzzetti, 1995) classifies what is exposed (humans, their property and resources such as water, land and cultural heritage) and how exposure can be reduced (through 'fortification capability'). These three bodies of theory are considered by Shi to be one-sided as they focus on a dominant factor but ignore other important factors. He states instead that "disaster is the product of abnormal process on the surface of the earth and resulted from the combined effect of the hazard, disaster-formative environment and exposure" (p.56). He combines insights from the three to propose a "regional disaster system theory", which builds on Burton et al. (1978), Blaikie et al. (1994), and Mileti (1999).

Regional disaster system (区域灾害系统) ${ }^{6}$ theory aims to be a comprehensive and holistic theory of disasters, where a disaster is the product of the interactions between hazard, disaster-formative environment, and exposure. In it, "the regional disaster system is essentially the product of the interaction of humans with nature" (authors' emphasis, p.58) and has rules of spatial and temporal differentiation. This allows for the possibility of elaborating regional differences and zoning.

\footnotetext{
${ }^{6}$ Shi classifies this as a social-ecological system, in which the exposure is the social system (human beings and their activities), disaster-formative environment is the ecological system and hazard is an emergent property formed by their interactions $(2019$, p.62)
} 
The disaster system is divided into three sub-systems: natural, environmental (i.e., naturehuman interactions), and human, on the basis of the classification of three types of hazard. The structural elements of the system, or ontology, are that it consists of the 'hazard' (灾害), 'exposure' (暴露) ${ }^{7}$, and disaster-formative environment. Where these overlap is the 'special space' (特殊空间), in which disasters occur. Each structural element of the system is assigned a functional characteristic which are all inter-related: the 'sensitivity' (灵敏度) of the disasterformative environment, the 'danger' (危险) of the hazard, and the 'vulnerability' (脆弱性) of the exposure. The use of the terms 'danger' and 'vulnerability' here is different and disruptive compared with the standard meanings in English. Vulnerability is used as a characteristic of the exposed assets, referring to their weakness and fragility, and danger is used as an adjective ('dangerousness') to describe the hazard, perhaps meaning its potential to cause destruction. This example highlights the difficulties of foreignised translation, where native speakers then have to learn a new meaning for the terminology or may not fully comprehend the original meaning.

The existence of 'rules' - science is the answer

Underlying the policies of regionalisation, functional zoning and ecological civilisation is a belief in the existence of objective 'rules' that govern and constrain human activity, for example the optimum number of people and economic activities for an area. The better the rules are known and applied, the better humans can thrive and develop. This view stems from dialectic materialism, in which the aim of research is to understand an objective reality, through its objective laws ${ }^{8}$.

"...human has to rely on their environment as basis for their survival and activities. Thus human should actively understand and consciously use and change land according to its rules so as to make land serve human better. That is the so-called objective human-environment relationship" (Fan, 2016, p.179, authors' emphasis)

Discovering these objective rules or laws for human-environment interaction becomes the objective of scientific research efforts, ostensibly to better inform central, regional and local

\footnotetext{
${ }^{7}$ Exposure is used here as a noun, describing the exposed elements (i.e. humans and immovable and movable property)

${ }^{8}$ See for example Xi, Jinping, 2019, Dialectical materialism is the worldview and methodology of Chinese communists, Qiushi Journal, Vol. 11, No. 1.
} 
spatial planning of living, production and ecological space. In this way of thinking, disasters occur because of a lack of knowledge or application of these objective rules, and the solution is to gain more scientific knowledge and apply it more rigorously.

\section{Conclusions}

Identification of ontological differences in interdisciplinary and cross-cultural research collaborations and working across these boundaries is challenging. The ontology the researchers relate to and work within, influenced by our education system or social background, are rarely questioned or evaluated. Rarer still are other ontologies considered. Nevertheless, considering ontological assumptions behind different views on the causes of disaster, within and across cultures, is an important path for collaboration and further research. We thus suggest that the following questions should be considered: What is the societal goal/aim? What is nature? What is society? How do these interact to create disasters? And what are the implications for DRR research and practice?

Through examining key 'translational' literature, the authors reflected on the goal of harmonious human-environment relationships and the view of disaster as a failure to coordinate this relationship. In China, central decision-making has shifted to policies that support "ecological civilisation" as the route to sustainable development (Chen et al., 2020). Centralised decision-making and the variety of geographical conditions mean that China has tended towards the use of spatial planning and zoning to coordinate the relationship and the discovery of the rules and associations that would enable this. A focus on science providing the answers has much in common with Western enlightenment thinking.

It was not our aim to delve deeply into philosophy and language to unpick the influence of different streams of thinking (Buddhism, Confucianism, Marxism, Humanism etc.) nor to provide a definitive account, but rather to suggest a new perspective with much scope for further exploration: How can we be aware of and allow critique of our ontologies?

In carrying out such a review, at the level of concept and ontology, we hope to continue and expand disaster dialogues from different perspectives, furthering mutual understanding, acknowledging how different ontologies impact the process of research, and its implications and impacts on wider practice, policy and society. Sensitivities and dilemmas exist, in seeking to describe elements of another culture - for example, over-simplification, generalisation and 
misinterpretation. Yet from within our own framework (be that a culture, a paradigm etc.), it can be difficult to identify internalised norms. By exploring other perspectives rigorously, without making assumptions, we are enabled to see our own viewpoint and its biases more clearly. As Liang Shuming wrote "Chinese people will never gain a clear understanding if they only remain within the structures of Chinese society; if only they first look to others and then at themselves, then they will immediately understand" (Liang, in Lu and Zhao, 2009 p. 50). The same is true for all cultures and societies. Looking in on one's own perspective from an outsider's point of view is an invaluable tool for gaining understanding. Such discussions can be fruitful if we begin the conversation as a dialogue, with humility, aiming to gain insight not just into another perspective, but also into our own.

\section{References}

Barbalet, J. (2020), "The Analysis of Chinese Rural Society : Fei Xiaotong Revisited", Modern China, No. January, available at:https://doi.org/10.1177/0097700419894921.

Benton, T. and Craib, I. (2001), Philosophy of Social Science the Philosophical Foundations of Social Thought, Palgrave, Basingstoke.

Bhatt, M.R. and Gaillard, J.C. (Eds.). (2020), The Contribution of Zenaida Delica-Willison to Disaster Risk Reduction, Vol. 76, All India Disaster Mitigation Institute, Ahmedabad, India, available at: http://www.elsevier.com/locate/scp.

Van Buuren, A., Edelenbos, J. and Warner, J. (2012), "Space for the River: governance and lessons", in Warner, J.F., Van Buuren, A. and Edelenbos, J. (Eds.), Making Space for the River, IWA Publishing, London, pp. 187-201.

Cablitz, G.H. (2001), “Geographical categories: An ontological investigation”, International Journal of Geographical Information Science, Vol. 15 No. 7, pp. 591-612.

Carrara, A. and Guzzetti, F. (Eds.). (1995), Geographical Information Systems in Assessing Natural Hazards, Springer Netherlands, Heidelberg.

Castree, N. and Braun, B. (2001), Social Nature - Theory, Practice and Politics, Blackwell Publishing, Malden. 
Chambers, R. (1994), "Participatory rural appraisal (PRA): analysis of experience", World Development1, Vol. 22 No. 9, pp. 1253-1268.

Cheek, W. and Chmutina, K. (2021), “'Building Back Better' is Neoliberal Post-Disaster Reconstruction", Disasters (in press).

Chen, G. (2016), The Politics of Disaster Management in China, Palgrave, New York.

Chen, M., Liang, L., Wang, Z., Zhang, W., Yu, J. and Liang, Y. (2020), “Geographical thoughts on the relationship between 'Beautiful China' and land spatial planning", Journal of Geographical Sciences, Vol. 30 No. 5, pp. 705-723.

Chmutina, K. and von Meding, J. (2019), “A Dilemma of Language: 'Natural Disasters' in Academic Literature", International Journal of Disaster Risk Science, Beijing Normal University Press, Vol. 10 No. 3, pp. 283-292.

Chmutina, K., Sadler, N., von Meding, J. and Abukhalaf, A.H.I. (2020), "Lost (and found?) in translation: key terminology in disaster studies", Disaster Prevention and Management, Vol. 30 No. 2, pp. 149-162.

Coutaz, G. (2018), “China: Disaster Preparedness, Response, and Recovery”, in Coutaz, G. (Ed.), Coping with Disaster Risk Management in Northeast Asia: Economic and Financial Preparedness in China, Taiwan, Japan and South Korea, Emerald Publishing Limited, pp. $31-60$.

Danermark, B. (2019), “Applied interdisciplinary research : a critical realist perspective”, Journal of Critical Realism, Vol. 18 No. 4, pp. 368-382.

Eddy, J.A. (Ed.). (1986), Global Change in the Geosphere-Biosphere, National Academy Press, Washington D.C.

Fan, J. (2016), How Chinese Human Geographers Influence Decision Makers and Society, The Geographical Society of China Book Series 16-02, The Commercial Press, Beijing, available at: http://www.geogsci.com.

Feyerabend, P. (1978), Science in a Free Society, Verso, London.

Froude, M.J. and Petley, D.N. (2018), "Global fatal landslide occurrence from 2004 to 2016", 
Natural Hazards and Earth System Sciences, Vol. 18 No. 8, pp. 2161-2181.

Gad-el-Hak, M. (Ed.). (2008), Large-Scale Disasters: Prediction, Control, and Mitigation, Cambridge University Press, Cambridge, available at:https://doi.org/DOI: 10.1017/СВO9780511535963.

Gaillard, J.C. (2019), “Disaster studies inside out”, Disasters, Vol. 43 No. S1, pp. S7-S17. GFDRR. (2020), Learning from Experience Insights from China's Progress in Disaster Risk Management, Washington D.C.

Ha, K.M. (2018), “The role of Confucianism in South Korea's emergency management system", Disasters, Vol. 42 No. 4, pp. 804-822.

Jiang, L. (2013), "Implementation of disaster reduction measures and enhancement of integrated risk governance in China", International Journal of Disaster Risk Science, Vol. 4 No. 2, pp. 101-104.

Kuhn, B. (2019), Ecological Civilisation in China, Expert Comment, Berlin, available at: https://doc-research.org/2019/08/ecological-civilisation-china-berthold/.

Kuhn, T.S. (1970), The Structure of Scientific Revolutions, 2nd ed., University of Chicago University Press, Chicago.

Li, P. (1996), Report on the Outline of the Ninth Five-Year Plan (1996-2000) for National Economic and Social Development and the Long-Range Objectives to the Year 2010 (Excerpts), available at: http://www.china.org.cn/95e/95-english1/2.htm.

Liu, K., Tang, M., Liu, R. and Qin, Y. (2017), “Geography's 'World view': the ontological issues of geography", Journal of Geographical Sciences, Vol. 27 No. 12, pp. 1541-1555.

Lu, W. and Zhao, X. (2009), "Liang Shuming's viewpoint of chinese and western cultures in The Substance of Chinese Culture", Contemporary Chinese Thought, Vol. 40 No. 3, pp. $52-66$.

Luo, P., He, B., Takara, K., Xiong, Y.E. and Nover, D. (2015), "Historical assessment of Chinese and Japanese flood management policies and implications for managing future floods", Environmental Science and Policy, Elsevier Ltd, Vol. 48, pp. 265-277. 
n.a. (2019), "Power, prestige and forgotten values: a disaster studies manifesto", available at: https://www.ipetitions.com/petition/power-prestige-forgotten-values-a-disaster (accessed 5 July 2019).

O'Keefe, P., Westgate, K. and Wisner, B. (1976), "Taking the naturalness out of natural disasters", Nature, Vol. 260 No. 15, pp. 566-567.

Parker Waller, P. and Flood, C.T. (2016), “Mathematics as a universal language: transcending cultural lines", Journal for Multicultural Education, Emerald Group Publishing Limited, Vol. 10 No. 3, pp. 294-306.

Peck, J. (2010), Construction of Neoliberal Reason, Oxford University Press, Oxford.

Perkins, F. (2019), "Metaphysics in Chinese Philosophy", The Stanford Encyclopedia of Philosophy2, Metaphysics Research Lab, Stanford University, available at: https://plato.stanford.edu/archives/sum2019/entries/chinese-metaphysics/.

Qian, X.S. (1954), Engineering Cybernetics, McGraw-Hill Book Company Inc., New York.

Saull, R. (2017), "Hegemony and the Global Political Economy", Oxford Research Encyclopedia of International Studies, Oxford University Press, available at:https://doi.org/10.1093/acrefore/9780190846626.013.208.

Shi, P. (2019), Disaster Risk Science, Springer, Singapore, available at: https://doi.org/10.1007/978-981-13-6689-5_5No Title.

Shi, P., Xu, W. and Wang, J. (2016), Natural Disaster System in China, edited by Shi, P., Beijing Normal University Press and Springer-Verlag, Berlin, available at:https://doi.org/10.1007/978-3-662-50270-9.

Smith, L.T. (2012), Decolonizing Methodologies, 2nd ed., Otago University Press, Dunedin. State Council of China. (2006), 11th Five-Year Plan for National Economic and Social Development (English), available at: https://policy.asiapacificenergy.org/node/115.

Stoddart, D.R. (1987), "To claim the high ground: geography for the end of the century.", Transactions - Institute of British Geographers, Vol. 12 No. 3, pp. 327-336. 
Tambassi, T. (2017), The Philosophy of Geo-Ontologies, Springer, Cham, Switzerland.

UNDRR. (2009), UNISDR Terminoology on Disaster Risk Reduction, available at: www.unisdr.org/publications.

Wittfogel, K.A. (1957), Oriental Despotism: A Comparative Study of Total Power, Yale University Press, New Haven. 